\title{
An Evaluation of the Ontario Farm Business Management Association Program
}

\author{
Wayne H. Howard ${ }^{1}$ and Glen C. Filson ${ }^{2}$ \\ ${ }^{1}$ Associate professor, Department of Agricultural Economics and Business, \\ University of Guelph, Guelph, Ontario. \\ ${ }^{2}$ Associate professor, Department of Rural Extension Studies, \\ University of Guelph, Guelph, Ontario.
}

The Ontario Farm Business Management Association (FBMA) program was initiated to improve the business management skills of Ontario red meat producers. The program has three aims:

- to increase management skills on the farm

- to increase management skills in the private sector

- to help farmers make use of private sector advice.

Two methods were used to evaluate the program. First, FBMA members and other red meat producers were surveyed about their farm and personal characteristics as well as use farm records and information sources. Second, focus groups were held with the FBMA fieldpersons. Results indicate that membership in an FBMA increased the collection and use of farm records, but that there was no significant increase in the use of private sector consultants by the producers. Moreover, FBMA members indicated a very low willingness to pay to support their FBMA if government funding were stopped.

L'objective du Programme des groupements de gestion de l'entreprise agricole de l'Ontario (PGGEA) était d'améliorer les compétence de gestion d'entreprise des producteurs de viande rouge de la province. Plus précisément, il visait à accroître les compétences de gestion tant à la ferme que dans le secteur privé et à aider les chefs d'exploitation à recourir aux conseils du secteur privé. Deux méthodes étaient utilisées pour évaluer le programme. En premier lieu, les membres des GGEA et les autres producteurs de viande rouge étaient intérrogés sur leurs caractéristiques personnelles et sur celles de leur exploitation, ainsi que sur leur utilisation des relevés d'exploitation et sur leurs sources d'information. Deuxièmement, des groupes de discussion étaient organisés avec des agents techniques des GGEA. Les résultats montrent que l'adhésion à un GGEA accroissait la prise et l'utilisation des relevés d'exploitation, mais qu'elle n'accroissait pas de façon significative le recours des producteurs aux conseillers du secteur privé. De plus, les membres des GGEA étaient très peu disposés à assurer eux-mêmes la survie financière de leur groupement, si l'aide financière de l'État leur était enlevée.

\section{INTRODUCTION}

Agricultural extension programs are designed to transfer knowledge about new and emerging technologies as well as existing methods to those who can benefit from that knowledge. Many programs have focused on increasing knowledge about farm business management methods, e.g., production and financial records and the use of those records in decision making. As these programs are government-funded, it is in the public interest to estimate the effectiveness of these programs in terms of increasing management skills and decision-making abilities in production agriculture. 
One such program for Ontario red meat producers is the Farm Business Management Association Program (FBMA). This program is unique in that its aim is not only to "... improve the farm management decision-making abilities of Ontario farmers ..." but also to develop ". . . . the private sector to better serve the management needs of farmers" and to prepare "... farm managers to use the private sector for business management advice'" (Government of Ontario 1989). Hence, the program has three aims:

- to increase management skills and decision-making abilities on the farm

- to increase management skills and decision-making abilities in the private sector

- to help farmers make use of private sector advice.

These three aims differentiate the program from more traditional programs directed solely at the farmer.

This paper reports on a mid-program evaluation of the FBMA. The objectives of the evaluation were to:

- identify the clientele of the FBMA in terms of personal and farm characteristics

- estimate the impact of the FBMA on the members' use of farm business records and private sector business advisors

- estimate the impact of the FBMA on the private sector.

Two methods were used to meet the objectives. First, a survey of FBMA members and other red meat producers was used to identify the characteristics of FBMA members and to estimate the impact of the FBMA on members' use of records and private sector advisers. Second, focus groups were the basis of a qualitative assessment of the impact of the program on the private sector.

\section{BACKGROUND}

Formal studies on the returns to extension have only recently emerged. Early studies that aggregated research and extension reported very large positive returns, but these studies did not disaggregate the returns to extension separately from those to research (Griliches 1964; Evenson 1968). Even evaluations of extension programs separate from research have tended to implicitly aggregate research and extension:

[extension] . . . has contributed significantly to the rate of growth in productivity and efficiency of U.S. agriculture. Most of this contribution has been because of extension's ability to increase the rate of adoption of new technology and knowledge generated by agricultural research. (USDA 1980, 151)

More recent studies have explored contributions from extension separately from research, and have found that extension contributes positively to the efficiency of agricultural production, with total social returns from agricultural extension programs ranging from $15 \%$ to $110 \%$ (Huffman 1974; Evenson 1978; Feder, Lau and Slade 1987).

Extension programs in financial management are generally thought to contribute to the overall management of farm operations, and were among the extension education topics most requested by U.S. midwest farmers, regardless of farm size or type of operation (Carter and Batte 1993). ${ }^{1}$ An evaluation of extension financial management programs in 37 states in the U.S. for the period 1984-88 found very positive returns. Some $71 \%$ of the respondents felt that their financial skills had improved because of their participation in an extension financial management program, and $88 \%$ indicated that their profitability had increased an average $\$ 20,000$ a year as a result of the program (Klair 1991). Though a formal cost-benefit evaluation was not part of the study, the study concluded that the expenditure on the financial management program was cost effective and beneficial.

Many U.S. states have increased farmers' financial management skills through FBMA 
programs. An evaluation of the programs in 1986 concluded that the associations were an effective and efficient way to teach management skills, and that both financial and production planning were improved due to added information and comparison with similar farms (Brown 1986). On average, the farmers surveyed had been association members for 14 years, and $80 \%$ stated a willingness to pay higher fees if necessary to continue the program. As with similar studies, a formal cost-benefit analysis of the program was not done.

Studies in Canada have also found that group study in the form of a farm management association is associated with increased management skills, but that the relationship between membership in an association and increased skills may be complementary and not causal. Doucharme and Rouillard (1991) surveyed dairy farmers in eastern Ontario to establish a base line for a future evaluation of the Groupement de gestion agricole program. Using a standardized test to measure management levels, they found that farmers who had recently joined a farm management group had significantly higher management skills than farmers who had not joined one. However, at the time of the initial survey, the farm management groups had not been in existence long enough to determine their effect on skill levels of members.

\section{FARM BUSINESS MANAGEMENT ASSOCIATIONS}

The Ontario Ministry of Agriculture and Food (OMAF) was given authority by an Order in Council to start the FBMA program for red meat producers in June 1989. "Red meat" included beef, lamb and chevon (goat). ${ }^{2}$ The objectives of the program were as outlined above. The design of the program was that OMAF would provide an annual grant to an FBMA of $\$ 500$ per eligible farm enrolled to a maximum of $\$ 10,000$ per FBMA, for five years commencing in fiscal 1989-90. Funding was available for a maximum of 50 associations. In order to receive the grant, the FBMA agreed to:
- maintain an enrolment of 10 to 20 eligible farmers

- conduct at least 36 hours of management education per year for its members

- require members to submit financial information to the Ontario Farm Management Analysis Project (OFMAP) $^{3}$ (for which the farmer received $\$ 500)^{4}$

- require members to submit Red Meats II (RM) ${ }^{5}$ production records to OMAF

- hire a "fieldperson" to teach and monitor record keeping (Government of Ontario 1989).

As of January 1992, there were 34 operatng FBMAs in Ontario, with approximately 400 registered members and 32 fieldpersons. When asked if they thought that there would be new FBMAs starting in the near future, OMAF administrators, fieldpersons and agriculture representatives did not foresee many, if any, new associations starting. Moreover, due to budget cutbacks, no new groups could be funded after the fiscal year ending 31 March 1992.

\section{METHODS}

In order to identify the clientele of the FBMA in terms of differences from other red meat producers and to estimate the impact the FBMA on the members' use of farm business records, surveys were sent out in spring 1992 to three groups of red meat producers:

- FBMA members (394 producers)

- red meat producers who had submitted OFMAP (financial) records and Red Meats II (production) records (502 producers)

- producers who had submitted only Red Meats II production records.

All producers from the first two groups were surveyed. Approximately 500 producers from among the more than 7,400 producers enrolled in the Red Meats II program were randomly sampled and sorted to ensure that they were not also enrolled in OFMAP and/or FBMA. A sample of this size was expected to provide sufficient degrees of freedom for statistical analysis. 
Table 1. Response rates and farm and personal characteristics of Red Meat, OFMAP and FBMA producers

\begin{tabular}{|c|c|c|c|}
\hline & Red Meat & OFMAP & FBMA \\
\hline \multicolumn{4}{|l|}{ Farm characteristics: } \\
\hline Number of surveys sent & 479 & 502 & 394 \\
\hline Response rate & $55 \%$ & $73 \%$ & $75 \%$ \\
\hline \multicolumn{4}{|l|}{ Number of acres: } \\
\hline In crops & 139 & 147 & 172 \\
\hline In pasture & 104 & 130 & 118 \\
\hline Owned & 199 & 225 & 194 \\
\hline Rented/leased & $93^{\mathrm{a}}$ & $135^{\mathrm{a}}$ & 128 \\
\hline Number of cows calving & 26 & 29 & 28 \\
\hline Head sold last year (feedlot) & 75 & 81 & 95 \\
\hline Number of ewes lambing & $15^{\mathrm{b}}$ & $12^{\mathrm{c}}$ & $26^{b, c}$ \\
\hline Number of does kidding & $7^{\mathrm{ab}}$ & $1^{a}$ & $2^{b}$ \\
\hline Total farm assets & $\$ 357,000$ & $\$ 310,000^{c}$ & $\$ 445,000^{c}$ \\
\hline Total debt & $\$ 81,000$ & $\$ 76,000$ & $\$ 84,000$ \\
\hline Farm net income & $\$ 0-15 \mathrm{k}^{\mathrm{b}}$ & $\$ 0-15 \mathrm{k}$ & $\$ 0-15 k^{b}$ \\
\hline Total family income & $\$ 15-30 k$ & $\$ 15-30 \mathrm{k}$ & $\$ 15-30 \mathrm{k}$ \\
\hline \multicolumn{4}{|l|}{ Personal characteristics: } \\
\hline Age & $48^{a, b}$ & $45^{\mathrm{a}}$ & $45^{\mathrm{b}}$ \\
\hline$\%$ female & $6^{\mathrm{a}, \mathrm{b}}$ & $11^{\mathrm{a}}$ & $15^{\mathrm{b}}$ \\
\hline No. of dependents & 2.4 & 2.4 & 2.4 \\
\hline Education & high school ${ }^{a, b}$ & some college $e^{a, c}$ & college $\operatorname{grad}^{\mathrm{b}, \mathrm{c}}$ \\
\hline \multicolumn{4}{|l|}{ On-farm work, self } \\
\hline Weeks per year & $44^{\mathrm{a}}$ & $47^{a}$ & 46 \\
\hline Hours per week & 39 & 40 & 38 \\
\hline \multicolumn{4}{|l|}{ Off-farm work, self } \\
\hline Weeks per year & 22 & 23 & 22 \\
\hline Hours per week & $23^{\mathrm{b}}$ & 19 & $18^{\mathrm{b}}$ \\
\hline \multicolumn{4}{|l|}{ On-farm work, spouse } \\
\hline Weeks per year & 25 & 28 & 25 \\
\hline Hours per week & $23^{\mathrm{b}}$ & $23^{c}$ & $15^{\mathrm{b}, \mathrm{c}}$ \\
\hline \multicolumn{4}{|l|}{ Off-farm work, spouse } \\
\hline Weeks per year & $20^{\mathrm{b}}$ & $19^{c}$ & $24^{\mathrm{b}, \mathrm{c}}$ \\
\hline Hours per week & 14 & 15 & 17 \\
\hline No. farm ed. meetings attended & 4 & $5^{\mathrm{c}}$ & $14^{b, c}$ \\
\hline \multicolumn{4}{|l|}{ No. of organizations: } \\
\hline Agricultural & $1^{\mathrm{b}}$ & $1^{c}$ & $3^{b, c}$ \\
\hline Other & $0.16^{\mathrm{ab}}$ & $0.25^{\mathrm{a}, \mathrm{c}}$ & $3^{\text {b.c }}$ \\
\hline
\end{tabular}

${ }^{a}$ Significant difference at the 0.05 level between Red Meat and OFMAP.

${ }^{b}$ Significant difference at the 0.05 level between Red Meat and FBMA.

${ }^{\mathrm{c}}$ Significant difference at the 0.05 level between OFMAP and FBMA.

All respondents were asked about their use of farm financial and production records, farm and personal characteristics, and business strategy. In addition, FBMA members were asked about their keeping and use of financial and production records before and after 
their involvement with the FBMA. In addition to yes/no, numerical (e.g., number of cows calving) and categorical (e.g., farm's net income before tax was less than zero, $\$ 0$ to $\$ 15,000$, etc.) types of questions, two types of Likert scales were used to elicit attitudes and beliefs about various types of records, professional services, and benefits and effects from FBMA membership. One type elicited a ranking of relative importance $(1=$ very important, $5=$ not important). The other type was a four-level scale of agreement/disagreement with a statement.

A $t$-test assuming that the variances of the responses were not the same was used to determine whether the responses between the groups were significantly different (Snedecor and Cochran 1967, 115). Where responses could be ranked, a Spearman rank correlation (p. 194) was used to determine whether the ordering of responses were significantly different across the three groups. A step-wise logit model (Judge et al 1980, 597-605, 727) was used to determine which characteristics were associated with willingness to pay to continue the FBMA.

The possibility of biased responses is recognized; if the FBMA members were satisfied with their association, then there may be a tendency to overrate the impact of the FBMA on their management practices and use of records. However, no base line surveys were done at the beginning of the FBMA program for comparison purposes. Recall questions are not preferred, but they are the best that can be done in this situation. Survey design and procedures followed Dillman (1978). Copies of the survey and cover letter are available from the authors upon request.

Focus groups were held with fieldpersons in order to determine their characteristics and to elicit their attitudes and opinions about the success of the FBMA and its impact on the private sector. A brief survey was used to obtain their economic and demographic characteristics, and openended questions and discussion were used to elicit their attitudes and beliefs about the FBMA program.

\section{RESULTS OF THE FARMER SURVEY}

Surveys were mailed in spring 1992 . In total, 1375 surveys were distributed, with 926 returned. The return rate by category ranged from $75 \%$ for the FBMA members to $55 \%$ for the RM producers. Specific returns by category are reported in Table 1.

\section{Farm Characteristics}

There were more similarities than differences among the respondents in terms of farm characteristics, as reported in Table 1. OFMAP producers rented/leased more land than did RM producers, but otherwise farm sizes were similar. There were no significant differences between the groups in the number of cows calving or number of head sold, but FBMA producers had larger sheep operations than did the other two groups, while RM producers had larger goat operations than the other two. ${ }^{6}$ Total farm assets were significantly larger for FBMA producers compared with OFMAP producers, but not compared with RM producers. Total debt and total family income was about the same across the three groups. Farm net income was reported in categories (e.g., $\$ 0-15,000, \$ 15,001-$ 30,000 , etc). While all three groups' average farm net income was in the $\$ 0-15,000$ category, there were more RM producers than FBMA producers in higher farm net income categories. In terms of business organization, RM and FBMA producers had more sole proprietorships than did OFMAP producers, who reported more partnerships and corporations.

\section{Personal Characteristics}

In terms of personal characteristics, RM producers were older, were more predominately male, and had less formal education than the other two groups (Table 1). The FBMA members had the highest level of formal education. OFMAP producers reported working slightly more weeks per year on the farm than did RM producers, but the hours worked per week were basically the same for all three groups. Off-farm work was basically the same for all three groups. 
Table 2. Mean responses of different producer categories regarding their business strategy

\begin{tabular}{lccc}
\hline & Red Meat & OFMAP & FBMA \\
\hline 1. Profit maximization is my top priority. & 1.82 & 1.86 & 1.85 \\
2. Farm growth is limited only by profits and technical skills. & 2.09 & 2.19 & 2.15 \\
3. It is more important to me to enjoy my family and rural living & & & \\
than to make a lot of money. & 1.71 & 1.74 & 1.78 \\
4. It is important to me that the farm stays in the family. & $1.82^{\mathrm{a}, \mathrm{b}}$ & $2.03^{\mathrm{b}}$ & $2.09^{\mathrm{a}}$ \\
5. Success in farming is up to me. & 1.90 & 1.91 & 1.82 \\
6. I am pleased with my farm's business performance to date. & 2.15 & 2.16 & 2.26 \\
\hline
\end{tabular}

Scale: Agree $=1$, Somewhat agree $=2$, Somewhat disagree $=3$, Disagree $=4$

${ }^{a}$ Significant difference at the 0.05 level between Red Meat and FBMA.

${ }^{\mathrm{b}}$ Significant difference at the 0.05 level between Red Meat and OFMAP.

The RM producers did work a few more hours per week off-farm than members of the other two groups, but the difference was significant only between the RM and FBMA producers. The total time worked on and offfarm was more than 52 weeks per year for all three groups, indicating that for part of the year these producers worked two jobs. FBMA members' spouses worked more weeks offfarm than did spouses of the other groups, but the hours worked per week were basically the same for all three.

A significant difference in personal characteristics was that many FBMA members were joiners. Unlike the RM and OFMAP producers, they were more likely to be members in recreational, community and professional organizations as well as the FBMA. Their membership in the FBMA also meant that they attended significantly more farm education meetings than those in the other two groups.

Six questions were asked about business strategy (Table 2). While not comprehensive, similar questions have been used in other studies to classify farmers as more "entrepreneurial" or "traditional"' (Rosenberg and Turvey 1991; Howard et al 1991). Responses were not significantly different across the three groups, except that RM producers were in more agreement than the other groups that "It is important to me that the farm stay in the family."

\section{Financial Records}

The great majority of all producers kept financial and production records, but significantly fewer FBMA producers kept financial records before joining an FBMA (Table 3). All producers were asked to rank the importance of reasons for keeping records $(1=$ very important, $5=$ not important), which yielded an implicit rank ordering of the reasons. All groups ranked "tax purposes" as the most important reason for keeping records, but after that the rankings were different across the groups: Spearman rank correlation coefficients indicated that the groups' rankings were significantly different at the $5 \%$ level. "Government programs" was ranked second most important by RM and OFMAP producers, third by FBMA producers. RM producers ranked "farm planning" third, while OFMAP producers ranked "enterprise analysis" third and "farm planning"' fourth. FBMA members "before FBMA" and the other groups ranked "market strategy" the least of their reasons for keeping records; FBMA members "after FBMA" ranked bankers and lenders last.

\section{Production Records}

Production records were similar to financial records. The majority of all producers kept them, but significantly fewer FBMA members kept them before the FBMA than did the other groups (Table 3). Not surprisingly, most 
Table 3. Farm financial and production records for Red Meat, OFMAP and FBMA producers before and after FBMA membership

\begin{tabular}{|c|c|c|c|c|}
\hline & Red Meat & OFMAP & $\begin{array}{l}\text { Before } \\
\text { FBMA }\end{array}$ & $\begin{array}{l}\text { After } \\
\text { FBMA }\end{array}$ \\
\hline \multicolumn{5}{|l|}{ \% keeping: } \\
\hline Financial records & $98^{\mathrm{b}}$ & $99^{\mathrm{a}}$ & $94^{\mathrm{a}, \mathrm{b}}$ & 100 \\
\hline Production records & $84^{b}$ & $90^{\mathrm{a}}$ & $69^{a, b}$ & $100^{c}$ \\
\hline \multicolumn{5}{|c|}{ Reasons for keeping financial records } \\
\hline \multicolumn{5}{|c|}{$(1=\text { most important, } 5=\text { least important })^{d}:$} \\
\hline Enterprise analysis & $2.76^{\mathrm{b}}$ & $2.22^{\mathrm{a}}$ & $3.41^{\mathrm{a}, \mathrm{b}}$ & $2.12^{\mathrm{a}, \mathrm{c}}$ \\
\hline Tax purposes & $1.37^{\mathrm{b}}$ & $1.35^{\mathrm{a}}$ & $1.59^{\mathrm{a}, \mathrm{b}}$ & 1.74 \\
\hline Market strategy & $2.92^{b}$ & $3.06^{\mathrm{a}}$ & $3.48^{\mathrm{a}, \mathrm{b}}$ & $2.79^{c}$ \\
\hline Gov't programs & $2.00^{\mathrm{b}}$ & $2.14^{\mathrm{a}}$ & $2.83^{\mathrm{a}, \mathrm{b}}$ & $2.14^{\mathrm{a}, \mathrm{c}}$ \\
\hline Bankers and lenders & $2.89^{\mathrm{b}}$ & 3.05 & $3.23^{b}$ & 3.00 \\
\hline Farm planning & $2.23^{\mathrm{b}}$ & $2.36^{\mathrm{a}}$ & $2.72^{a, b}$ & $2.64^{\mathrm{a}, \mathrm{c}}$ \\
\hline Monitor cash flows & $2.66^{b}$ & $2.80^{\mathrm{a}}$ & $3.12^{\mathrm{a}}$ & $2.60^{c}$ \\
\hline \multicolumn{5}{|l|}{$\%$ using services of: } \\
\hline Chartered accountants & $67^{b}$ & 61 & $57^{\mathrm{b}}$ & 60 \\
\hline Record-keeping services & 14 & 11 & 11 & 13 \\
\hline Tax filing service & 43 & 39 & 40 & 41 \\
\hline \multicolumn{5}{|l|}{$\%$ keeping production records on: } \\
\hline Animal health & $66^{a}$ & $70^{b}$ & $53^{a, b}$ & $82^{a, c}$ \\
\hline Breeding and due dates & 75 & 68 & $72^{\mathrm{a}, \mathrm{b}}$ & $79^{c}$ \\
\hline Sires of pregnant animals & 84 & 77 & 81 & 86 \\
\hline No. of offspring & $87^{\mathrm{a}, \mathrm{c}}$ & $79^{c}$ & $78^{a}$ & $87^{c}$ \\
\hline Weights of offspring & $75^{\mathrm{a}}$ & $70^{\mathrm{b}}$ & $58^{\mathrm{a}, \mathrm{b}}$ & $82^{\mathrm{a} . \mathrm{c}}$ \\
\hline B'date of offspring & $86^{\mathrm{a}, \mathrm{c}}$ & $79^{c}$ & $77^{\mathrm{a}}$ & $87^{\mathrm{c}}$ \\
\hline Sire and dam of offspring & $83^{a, c}$ & $73^{c}$ & $75^{\mathrm{a}}$ & $86^{c}$ \\
\hline Monthly livestock count & $60^{\mathrm{a}}$ & $64^{b}$ & $37^{\mathrm{a}, \mathrm{b}}$ & $61^{c}$ \\
\hline Purchase and selling weight & $76^{\mathrm{a}}$ & $78^{b}$ & $59^{\mathrm{a}, \mathrm{b}}$ & $82^{\mathrm{a}, \mathrm{c}}$ \\
\hline \multicolumn{5}{|l|}{ Type of record system used: } \\
\hline Paper & 98 & 97 & 96 & 95 \\
\hline Self-designed computer program & $6^{b}$ & 12 & $12^{b}$ & $19^{\mathrm{c}}$ \\
\hline Purchased computer program & 2 & 5 & 4 & $13^{a, b, c}$ \\
\hline
\end{tabular}

${ }^{a}$ Significant difference at the 0.05 level between FBMA and OFMAP.

${ }^{\mathrm{b}}$ Significant difference at the 0.05 level between FBMA and Red Meat.

${ }^{\mathrm{c}}$ Significant difference at the 0.05 level before and after FBMA.

${ }^{\mathrm{d}}$ Spearman rank correlation coefficients: RM-OFMAP $=0.829$, RM-Before FBMA $=0.886$, OFMAP-Before FBMA $=0.543$, Before/After FBMA $=0.143$, RM-After FBMA $=0.543$, OFMAP-After FBMA $=0.828$.

producers kept paper records. Very few used a computer, but more FBMA and OFMAP producers used computers than did RM producers.

\section{Professional Services}

Two questions were asked about the use of professional services. First, respondents were asked if they subscribed to the services or accountants or record keeping/tax filing services to keep some or all of their farm business records. There was a small significant difference between RM and "before FBMA" producers using chartered accounts, but otherwise there was no significant difference in the 
Table 4. Percentage professional services used

\begin{tabular}{lccc}
\hline & Red Meat & OFMAP & FBMA \\
\hline Accountant or financial adviser & $55^{\mathrm{a}}$ & 60 & $65^{\mathrm{a}}$ \\
Farm management association agent & $9^{\mathrm{a}}$ & $13^{\mathrm{b}}$ & $68^{\mathrm{a}, \mathrm{b}}$ \\
Tax preparer & 58 & 54 & 53 \\
Feed and supply technical rep. & $37^{\mathrm{a}, \mathrm{c}}$ & $48^{\mathrm{b}, \mathrm{c}}$ & $64^{\mathrm{a}, \mathrm{b}}$ \\
Crop/pest technical rep. & $24^{\mathrm{a}}$ & $36^{\mathrm{c}}$ & $36^{\mathrm{a}}$ \\
Computer software vendor & $4^{\mathrm{a}}$ & $9^{\mathrm{b}}$ & $20^{\mathrm{a}, \mathrm{b}}$ \\
Computer hardware vendor & $3^{\mathrm{a}}$ & $6^{\mathrm{b}}$ & $12^{\mathrm{a}, \mathrm{b}}$ \\
Farm management consultant & $14^{\mathrm{a}}$ & $20^{\mathrm{b}}$ & $37^{\mathrm{a}, \mathrm{b}}$ \\
Agriculture rep./farm management specialist & $40^{\mathrm{a}, \mathrm{c}}$ & $65^{\mathrm{c}}$ & $71^{\mathrm{a}}$ \\
OMAF livestock specialist & $37^{\mathrm{a}, \mathrm{c}}$ & $47^{\mathrm{b}, \mathrm{c}}$ & $71^{\mathrm{a}, \mathrm{b}}$ \\
University professor & $3^{\mathrm{a}, \mathrm{c}}$ & $7^{\mathrm{b}, \mathrm{c}}$ & $51^{\mathrm{a}, \mathrm{b}}$ \\
Agriculture college instructor & $5^{\mathrm{a}}$ & $7^{\mathrm{b}}$ & $14^{\mathrm{a}, \mathrm{b}}$ \\
Veterinarian & $89^{\mathrm{a}, \mathrm{c}}$ & $94^{\mathrm{b}, \mathrm{c}}$ & $14^{\mathrm{a}, \mathrm{b}}$ \\
\hline
\end{tabular}

${ }^{a}$ Significant difference at the 0.05 level between Red Meat and FBMA.

${ }^{b}$ Significant difference at the 0.05 level between OFMAP and FBMA.

${ }^{c}$ Significant difference at the 0.05 level between OFMAP and Red Meat.

use of record keeping/tax filing services between the three groups (Table 3 ).

Second, respondents were asked if they had used professional services in the past two years for a source of information; use varied considerably across the three groups. RM and OFMAP producers used veterinarians and tax preparers more (but not significantly more) than FBMA producers did, but otherwise FBMA producers used all professional services more than RM producers did, as reported in Table 4. Except for tax preparers, OFMAP producers also used all professional services more than RM producers did. As expected, FBMA members used farm management association agents much more than did the other groups. The RM and OFMAP producers who said that they used farm management association agents likely thought the question referred to another type of extension agent. The differences in the use of veterinarians, agriculture department representatives and OMAF livestock specialists, and university and college professors were surprising and not easily explained. The magnitudes of the differences, especially the much greater use of veterinarians by RM and OFMAP producers, were not expected. ${ }^{7}$

\section{Reasons for Joining an FBMA}

FBMA members were asked to rank the importance $(1=$ very important, $5=$ not important) of different reasons for joining their FBMA. The reasons in order of importance are reported in Table 5. "Learn more about production" was most important, followed by "Learn more about using financial records." The differences between the rankings were statistically significant, which implies that there was a clear ranking of importance.

\section{Impact of FBMA}

Inferences about the impact of the FBMA can be drawn from the FBMA members' responses reported in Table 3 . When asked to rank the reasons for keeping records before and after FBMA membership, the producers ranked "Tax purposes" first both before and after, but its rating decreased slightly after joining the FBMA. All the other reasons for keeping records were rated more important after joining the FBMA, but the rank order also changed (Spearman $r_{s}=0.143$ ). "Enterprise analysis" was sixth before joining the FBMA, but was second after. "Farm planning" and "Bankers and lenders", 
Table 5. Importance of reasons for joining FBMA (Scale: $1=$ very important, $5=$ not important)

Learn more about using financial records.

Learn more about production.

Learn more about using production records.

Comparison of businesses.

To ensure that FBMA received government grant.

Socialize with friends and neighbors.

${ }^{\mathrm{a}}$ Differences between rankings are significant at the $\alpha=0.01$ level.

${ }^{b}$ Numbers in parentheses are the variance of the response.

both decreased in importance after joining the FBMA, moving from second to fifth and fifth to seventh, respectively. "Marketing strategy" was seventh (and last) before membership, but moved up to fifth and second to the last after.

FBMA producers showed a small increase in the percentage using professional accounting and tax services, but the increase was not statistically significant.

The percentage of FBMA producers keeping various production records increased significantly after joining the FBMA, as reported in Table 3. Only one of the nine records, "Sires of pregnant animals," did not increase significantly.

More after-FBMA producers used computers with either a self-designed or purchased computer program with which to keep their financial and production records. The percentage using computers was still relatively small (less than a fifth), but the FBMA did have a significant effect on the number using computers.

In order to determine the effect of the FBMA on attitudes about and use of records, FBMA members were given a number of statements about the FBMA and asked if they agreed or disagreed with the statement on a scale of 1 (strongly agree) to 4 (strongly disagree). Results are reported in Table 6 . There was strong agreement (average response $<2.00$ ) that the respondents' association had been successful, that the fieldperson had provided competent, useful information, and that the member's understanding, use and accuracy of management tools had increased. Both financial and production records were considered to be more important after joining the FBMA. Agreement was weaker (average response $>2.00$ ) that membership in the FBMA gave the member a better understanding of what further training the member needed, helped the member to increase farm profits, or increased their sense of community or leadership skills.

An indication of the value of the FBMA to the members was their stated willingness to pay for the continuation of their association. When asked "How much would you be willing to pay for your FBMA to continue?" the average was $\$ 96$ per year. Almost $60 \%$ stated nothing per year, while only $3.3 \%$ stated $\$ 500$ per year, the amount of the government grant that supports the program. Most notable was the result of a step-wise logit model, which estimated that 50 characteristics/factors from the survey were not significantly associated (at the 0.05 level) with willingness to pay. Nine characteristics that were significant, either positively or negatively, are reported in Table 7. It is difficult 
Table 6. Effect of membership in an FBMA (Scale: $1=$ strongly agree, $4=$ strongly disagree)

Average

response

I feel that my association has been successful.

The field person has provided competent, useful farm business advice and/or services to association members.

My understanding and use of farm financial management tools has increased.

The accuracy of my financial and production records has improved.

I now consider financial records to be more important.

I now consider production records to be more important.

I have a better idea of what further training and education I need.

I have found ways to increase farm profits.

My sense of community and peer support has increased.

I feel that my leadership skills have improved.

${ }^{\mathrm{a}}$ Numbers in parentheses are the variance of the response.

Table 7. Characteristics and factors significantly associated with willingness to pay to support FBMA

Characteristic/factor ${ }^{\mathrm{a}}$

Increased sense of community and peer support

Joined FBMA to learn about using production records

Joined FBMA for gov't grant

Second most important crop not red meat

Number of ewes lambing

Female respondent

Weeks worked off-farm

Hours worked per week off-farm

Membership in professional organization

a 50 other characteristics/factors from the survey were not significantly associated with willingness to pay for FBMA.

to get a clear picture from the results. The satisfaction one received from the FBMA was positively associated with willingness to pay, but there were several other questions related to satisfaction with the FBMA. Weeks worked off the farm was negatively associated, but hours worked per week off the farm was positive. Membership in professional organizations was 
Table 8. Characteristics of FBMA fieldpersons

Characteristics

Mean value

Age

45

$(15.5)^{\mathrm{a}}$

Education

Primary occupation

Income from primary occupation

university degree

farming

$\$ 27,633$

$(14,260)$

Secondary occupation

consultant/fieldperson

Income from secondary occupation

$\$ 10,000$

$(6,000)$

Wage/salary as fieldperson

$\$ 4,885$

$(4,805)$

Number in sample

${ }^{\mathrm{a}}$ Standard deviation in parentheses.

negative, but FBMA members joined more organizations on average than did the other two groups of producers. Possibly the most one can say is that there was a low willingness to pay, but there did not appear to be any characteristics that independently defined that willingness.

\section{FIELDPERSON FOCUS GROUPS}

Two focus groups were held with FBMA fieldpersons; seven in one group, eight in the other. In part, the objectives of the FBMA program were to develop ". . . the private sector to better serve the management needs of farmers" and to prepare ". . . farm managers to use the private sector for business management advice"' (Government of Ontario 1989). Hence, it was important to determine the impact of the FBMA program on the private sector.

Descriptive statistics of the fieldpersons are reported in Table 8 . Their ages ranged from 24 to 68 , with a mean of 45 . Most had university degrees, two had college diplomas, and one had a graduate degree. The greatest frequency for primary occupation was farming, and a third listed farming as their secondary occupation. Only two did not currently farm at all.

There were basically three categories of fieldpersons. Those in the first group were retired, financially secure farmers who advised an FBMA in part for the supplemental income and in part as a voluntary community involvement. These people were not interested in building a clientele for further consulting. In some cases, the fieldperson was the instigator of the FBMA program activities, taking a large leadership and administrative role. In other cases a president or executive of the FBMA provided leadership and administration, and the fieldperson worked only as a business adviser.

Those in the second group were young, at the beginning of their careers. They worked with an FBMA in order to build a client base for further consulting and because the income as a fieldperson was a significant supplement to their primary income. These fieldpersons also provided a large administrative role for their FBMA.

The third group comprised two accountants who said their FBMA activities were an extension of their practices. Their hourly income from their FBMA activities was lower than their regular fee structure, but higher than what the other fieldpersons received. Their FBMA hired them for professional advice, and the administrative activities were handled by the executive of the FBMA.

Four broad questions were raised at the focus groups: 
- Have the associations been successful? How does one define success?

- What are the factors critical to the success of an FBMA?

- Have the fieldpersons benefited from their involvement with the associations?

- Would the associations continue without government funding?

All questions generated considerable discussion.

Two implicitly agreed-upon measures of success were members' benefits from their FBMA and continuing attendance. There was considerable anecdotal evidence that greater attention to financial records and comparing one's operations with those of one's neighbor were very beneficial. Keeping better record of feed costs and comparing feed costs were mentioned several times as resulting in savings for members. Association membership ranged from 12 to 20 , with 15 about average. Attendance varied from $50 \%$ to $75 \%$ at any meeting.

With respect to critical success factors, all agreed that it was important for an association's success to keep membership small, in the range of 12 to 15 . Leadership was also important to the continued success of an association. Whether that leadership was provided by a member or the fieldperson, it was critical that someone assume responsibility for the association. That responsibility included calling members about meetings, setting agendas, etc. A small geographical area for the membership was also important. Drawing from too large an area decreased attendance and member involvement.

All fieldpersons felt that they had benefited from their involvement in the program. They stressed their sense of personal satisfaction in helping others and how they learned more than they taught. However, only three fieldpersons had been contacted about individual consulting help. One of these fieldpersons was an accountant who was very happy about the success of his association and the resulting business for his practice. However, he appeared to be an exception. Another fieldperson had obtained some custom sheep-sheering work through his association.
There were mixed feelings about the role of government funding. There was agreement that the grant of $\$ 500$ per member per year was more than adequate to maintain an association, but there was considerable debate about the continuance of the associations without government funding. It appears that about half the associations would continue without government funding.

\section{DISCUSSION}

The survey results indicated that there were more similarities than differences between Red Meat II, OFMAP and the FBMA participants in terms of farm and personal characteristics. Number of acres owned, number of cows calving, total debt and total family income were not significantly different across the three groups. There were a number of significant differences, however, between RM and FBMA producers at the time they joined an association, both in characteristics and attitudes. RM producers were older, were more predominately male and had a higher net farm income. More important were the difference in records kept and reasons for keeping those records.

It is reasonable to characterize the RM producers as older, established commercial farmers, who understand the importance of maintaining good financial and production records. The high percentage of RM producers who used chartered accountants could indicate their appreciation of financial and tax analysis, or it could reflect their lower level of education and lack of interest or knowledge to do their financial records themselves. They also depend upon veterinarians for much of their advice.

The FBMA producers can be characterized as being younger, having a greater likelihood of being female, and being more likely to depend on extension and technical personnel for advice. However, the differences between the two groups diminished after joining the FBMA; records kept were different between the two groups before joining the FBMA but very similar after joining the FBMA. Before membership, 
significantly fewer FBMA than RM producers kept the nine production records listed in Table 3. After membership, there was no significant difference between the percentage of the groups keeping six of the records (Breeding and due dates, Sires of pregnant animals, Number of offspring, Birthdate of offspring, Sire and dam of offspring, Monthly livestock count), and significantly more FBMA producers kept three of the records than did RM producers (Animal health, Weights of offspring, Purchase and selling weight). Hence, if keeping records is an indicator of management skills, then membership in an FBMA appears to have increased the management skills of the FBMA members to the level of the RM producers.

A caveat is in order about the "before and after" questions. The responses are likely to be somewhat biased. An FBMA member who is pleased or at least satisfied with the association is likely to attribute a greater influence to the association than it might deserve. Also, active members in an organization are not likely to say that they are wasting their time in the organization. In effect, that would be criticizing their own actions. Hence, the impact of the FBMA on the members may be overstated in the "before and after" questions. However, even if overstated, the results indicate that membership in an FBMA affected the members' use of farm business records and attitudes about those records.

In examining the objectives of the FBMA program, it appears to have increased management skills on the farm, as indicated by the use of farm records, but the program's affect on management skills in the private sector is indeterminate, and there is no indication that FBMA membership has increased members' use of private sector advice. FBMA members reported increased keeping of financial and production records, and a difference in the reasons for keeping financial records after FBMA membership (Table 3). However, they reported a small and not significant increase in the use of accountants, tax and record-keeping services after the FBMA (Table 3). Moreover, only three fieldpersons reported any consulting activities with FBMA members separate from the FBMA activities, and none of the fieldpersons expected any additional consulting to be generated from their FBMA activities. Hence, results from both the survey and the focus groups indicated that the objective of increasing farmers' use of the private sector for business management advice was not achieved. Moreover, the farmers' low willingness to pay to continue their FBMA was an indicator of the members' perceived value of their FBMA. ${ }^{8}$

\section{CONCLUSION}

Membership in an FBMA had a positive effect on members' collection, maintenance and use of production and financial records. Both the records kept and attitudes about those records were different after membership in an FBMA. However, other than use and attitudes about records, there were few significant differences between RM, OFMAP and FBMA producers. It is possible that the FBMA raised younger, less experienced producers to a management level similar to that of the older, more experienced Red Meat II producers. If that is the case, then the program did contribute positively to the human capital in Ontario's red meat industry.

The program did not have a significant impact on the availability of rural business consultants to assist red meat producers with management decisions or on the demand for those consultants by farm managers. The reported increase in the use of private sector consultants by FBMA producers after membership in their FBMA was not significant. Moreover, even those advisers reporting a positive experience as a fieldperson with an FBMA did not expect an increase in demand for their services independent of the FBMA.

Lastly, FBMA members indicated a low willingness to pay to continue their FBMA. More than half were not willing to pay anything to continue support for their FBMA, and very few were willing to pay the $\$ 500$ per year currently being paid by the government. Results from both the farmer survey and the focus groups indicated that few producers 
were willing to financially support their FBMA. Hence, if the stated willingness to pay is an indication of the value of the FBMA program to its members, then the FBMA did little in increasing the management skills of the farmers involved.

\section{NOTES}

${ }^{1}$ Income tax management, price outlook for agricultural inputs and year-end financial analysis were ranked first, second and third in importance. ${ }^{2}$ Pork was not considered a red meat by the Ontario government in this program.

${ }^{3}$ OFMAP is a cooperative effort of farmers, OMAF and the University of Guelph. Farmers are paid $\$ 500$ to submit their financial records in a standardized format, which are then compiled by enterprise type into revenue and expenses statements in order to provide farmers and others with financial and physical information for management purposes and policy analysis.

${ }^{4}$ The $\$ 500$ payment to the farmer for submitting his/her financial records was separate from the grant to the FBMA. In effect, the FBMA program cost the Ontario government $\$ 1000$ per enrolled farmer, but the payment for the financial records for OFMAP were budgeted separately from the FBMA budget, and many farmers received the $\$ 500$ for submitting their financial records to the OFMAP program but did not join an FBMA.

${ }^{5}$ The Red Meats II program collected production information (e.g., weaning weights), which was then compiled by OMAF in order to provide red meat producers with industry production parameters for comparison, selection and culling purposes.

${ }^{6}$ The sheep and goat values may not be representative. There were so few sheep and goat operations that one or two herds can skew the values. ${ }^{7}$ There was considerable anecdotal evidence that veterinarians provided advice on more than animal health. Producers also asked veterinarians for advice on nutrition, production practices and breeding decisions, to name only a few areas.

${ }^{8} \mathrm{~A}$ reviewer suggested that FBMA members may think that stating a willingness to pay will increase the likelihood that they will have to pay the cost of the program. Hence, their stated willingness to pay may be much lower than their true willingness to pay.

\section{ACKNOWLEDGMENT}

This study was funded in part by the Ontario Ministry of Agriculture, Food and Rural Affairs.
The authors appreciate the comments and criticisms given by three anonymous Journal reviewers. All errors and opinions are solely those of the authors.

\section{REFERENCES}

Brown, Thomas G. 1986. National impact study: Financial planning and management programs farm business management associations. Columbia: University of Missouri and Lincoln University. Carter, Bryson R. and Marvin T. Batte. 1993. Identifying needs and audiences in farm management outreach education. Revue of Agricultural Economics 15 (3): 403-15.

Dillman, D. E. 1978. Mail and Telephone Surveys: The Total Design Method. New York: John Wiley and Sons.

Doucharme, Guy and Paul Rouillard. 1991. Dairy farms in eastern Ontario and members of farm management groups. Alfred, Ont.: College of Agriculture and Food Technology.

Evenson, Robert E. 1968. The contribution of agricultural research and extension to agricultural production. $\mathrm{PhD}$ thesis. Chicago, Ill.: University of Chicago.

Evenson, Robert E. 1978. Research, invention, extension and productivity change in U.S. agriculture: An historical decomposition analysis. Paper presented at the Symposium on Research and Extension Evaluation, Moscow, Idaho, 21-23 May. Feder, Gershon, Lawrence J. Lau and Rodger H. Slade. 1987. Does agricultural extension pay? The training and visit system in northeast India. American Journal of Agricultural Economics 69 (3): 677-86.

Government of Ontario. 1989. Ontario farm business management association program. Toronto: Order in Council, Ontario Executive Council, 23 July.

Griliches, Zvi. 1964. Research expenditures, education and the aggregate agricultural production function. American Economic Revue 54: 961-974. Howard, Wayne H., Kenneth A. McEwan, George L. Brinkman and Julia M. Christensen. 1991. Human resource management on the farm: Attracting, keeping, and motivating labour. Agribusiness: An International Journal 7 (1): 11-26.

Huffman, Wallace E. 1974. Decision making: The role of education. American Journal of Agricultural Economics 56 (1): 85-97.

Judge, George G., William E. Griffiths, R. Carter Hill and Tsoung-Chao Lee. 1980. The Theory and Practice of Econometrics. New York: John Wiley and Sons. 
Klair, Kevin S. 1991. National assessment of extension farm and ranch management programs 1984 through 1988. Minneapolis: University of Minnesota, Minnesota Extension Service, November. Rosenberg, Alexandro and Calum G. Turvey. 1991. Identifying management profiles on Ontario swine producers through cluster analysis. Review of Agricultural Economics 13 (2): 201-14.
Snedecor, George W. and William G. Cochran. 1967. Statistical Methods. 6th ed. Ames: Iowa State University Press.

United States. Department of Agriculture. Science and Education Administration - Extension. 1980. Evaluation of economic and social consequences of cooperative extension programs. Washington, D.C.: GPO. 